\title{
A FORMAÇÃO DO AGRÔNOMO NA AMAZÔNIA: PERFIL E DESAFIOS PARA A SUSTENTABILIDADE
}

\author{
Jorge Alan Quaresma de Sousa ${ }^{1}$; Erika Kzan da Silva ${ }^{1}$; Ruth Helena Cristo Almeida ${ }^{2}$; Cintya \\ Meireles de Oliveira ${ }^{3}$. \\ ${ }^{1}$ Discente de Agronomia da Universidade Federal Rural da Amazônia, jorge_quaresma100@hotmail.com \\ ${ }^{2}$ Docente da Universidade Federal Rural da Amazônia, ruth.almeida@ufra.edu.br \\ ${ }^{3}$ Docente da Universidade Federal Rural da Amazônia, cyntiamei@ hotmail.com
}

\begin{abstract}
RESUMO: A Amazônia é uma das últimas fronteiras agrícolas do Brasil. Para defender as riquezas esse patrimônio, tanto naturais quanto culturais, essa região necessita de profissionais capazes, com formação condizente com a conjuntura agrária em que vive. Entretanto, uma das principais instituições de ensino das Ciências Agrárias na região não capacita os estudantes de acordo com a demanda do "Rural da Amazônia". Percebemos esse fato quando questões intrínsecas da região como a Reforma Agrária e Soberania Alimentar deixaram de ser debatidas na maioria das disciplinas ofertadas na graduação em Agronomia. Uma nova proposta metodológica de ensino da Agronomia é urgente e necessária, de modo que rompa com o paradigma de desenvolvimento para o campo, e proponha a Agroecologia como método viável para, nesse primeiro momento, diminuir as crises ambientais e sociais existentes no campo Amazônico.
\end{abstract}

PALAVRAS-CHAVE: agronomia, Amazônia, formação profissional.

\section{THE AGRONOMIST TRAINING IN THE AMAZON: PROFILE AND CHALLENGES FOR SUSTAINABILITY}

\begin{abstract}
The Amazônia is one of the last agricultural borders of Brazil country. To defend this full patrimony of wealth, natural how much in such a way cultural, this region needs capable professionals, with formation condizente with the agrarian conjuncture where we live. However, one of the main institutions of education of Agrarian Sciences in the region does not enable the students in accordance with the demand of the "Agricultural one of the Amazônia". We perceive this fact when intrinsic questions of the region as the Agrarian Reformation and Alimentary Sovereignty had left of being debated the majority disciplines of them offered in the graduation in Agronomy. New a proposal metodológica of education of Agronomy is urgent and necessary, in way that breaches with the current paradigm of development for the field, and considers the Agroecologia as only viable method for, at this first moment, to diminish existing the ambient and social crises in the Amazonian field.
\end{abstract}

KEY-WORDS: agronomy, Amazônia, professional formation.

\section{INTRODUÇÃO}

O estudo da formação profissional, no âmbito das Ciências Agrárias, e em especial da Agronomia, nos remete a um resgate histórico da sua formação em suas diversas facetas. A própria criação da agronomia enquanto atividade profissional está atrelada à atividade agrícola quando o homem passa de extrativista a produtor, a fim de estabilizar sua família em uma determinada área, onde pudesse encontrar a oferta de alimentos básicos para sua manutenção. $\mathrm{O}$ aumento nas demandas gerava, em consequencia um acréscimo de mão-de-obra para a atividade. 
No início da década de 1960 o paradigma tecnológico da agricultura sofre drástica alteração com o advento da Revolução Verde. Novas tecnologias foram geradas para o campo. A utilização do conhecimento em genética e o aprimoramento dos estudos na química possibilitaram a criação de sementes melhoradas e agrotóxicos. Essa fase fica marcada pela venda de pacotes tecnológicos, ou seja, venda de elementos e técnicas que somente podem ser utilizados conjuntamente, seguindo-se as normas da pesquisa que a desenvolveram. Esse processo ocasionou uma dependência cada vez maior do produtor rural dos procedimentos técnicos para sua permanência na atividade.

Destarte, as universidades passam a capacitar profissionais, ignorando as relações sociais de produção e a realidade rural. Este foi um dos reflexos da política educacional adotada pelo processo da Revolução Verde, a fim de gerar um quantitativo de mão-de-obra capacitada para a mera difusão do pacote tecnológico a partir do método da persuasão, sem uma consciência crítica acerca dos impactos que tal atividade poderia gerar no campo. Para Milléo et al (1999), os profissionais das Agrárias formados a partir da ótica do tecnicismo apregoado pela Revolução Verde não têm conhecimento de alguma possível área de atuação e preferem ser empregados do que enfrentar dificuldades de trabalho como autônomos, pois é percebida a falta de habilidades e conhecimentos de formação humanística e social sendo difícil o tratamento com os diversos setores da sociedade.

Este artigo objetiva analisar como estão sendo formados os estudantes do curso de agronomia e se temáticas importantes como reforma agrária, segurança alimentar, pluriatividade, papel da mulher no meio rural estão sendo discutidos em sala de aula ou no âmbito deste curso.

\section{MATERIAL E MÉTODOS}

A pesquisa foi realizada a partir da coleta de dados, por meio de questionário estruturado, dirigido a 50 estudantes do curso de graduação em Agronomia da Universidade Federal Rural da Amazônia - UFRA, contemplando os semestres: $3^{\circ}, 5^{\circ}, 7^{\circ}$ e $9^{\circ}$. O formulário de questões continha perguntas objetivas dotadas de alternativas para respostas como "sim e não" e valores percentuais. As perguntas faziam referência aos conteúdos abordados nas disciplinas ministradas, objetivando caracterizar o enfoque central da formação do profissional.

\section{RESULTADOS E DISCUSSÃO}

Sessenta por cento dos estudantes, que estão cursando o $3^{\circ}$ semestre do curso de Agronomia, avaliaram na pesquisa nunca ter visto a abordagem do tema Reforma Agrária dentro das disciplinas do curso. Essa estatística, no decorrer do curso, não se altera de forma considerável, quando metade dos estudantes que estão cursando o $5^{\circ}$ e o $7^{\circ}$ 
semestre afirmam ter visto em apenas de $1 \%$ a 5\% das disciplinas a abordagem da Reforma Agrária.

Quando se faz uma análise dos estudantes que estão se formando, os dados são mais preocupantes, no que concerne aos conhecimentos acerca de como lidar com questão tão delicada. $80 \%$ dos estudantes que se encontram no $9^{\circ}$ semestre afirmam que apenas de $5 \%$ a $0 \%$ das disciplinas ofertadas durante toda a graduação trouxeram consigo o debate sobre a temática.

Em relação ao debate da Segurança Alimentar, mais da metade dos entrevistados diz ter visto essa temática inserida de $5 \%$ a $0 \%$ das disciplinas ofertadas no curso. E considerando os estudantes que estão se formando, esta estatística sofre ligeira alta, $70 \%$ dos entrevistados vem a dizer que de $25 \%$ para menos das disciplinas do curso debateram tal questão.

O percentual de disciplinas que trouxeram consigo o debate da Pluriatividade, nota-se que nos semestres inferiores ao $9^{\circ}$ esse debate foi trazido, na maioria das opiniões, de $5 \%$ a $0 \%$ das disciplinas ofertadas. Entretanto, no $9^{\circ}$ semestre esse debate sofre considerável alta, onde $60 \%$ dos estudantes afirmam que entre $26 \%$ a $50 \%$ das disciplinas promovidas pela graduação em agronomia tem o debate da pluriatividade.

A região Amazônica é marcada por uma gama de povos e conhecimentos, culturas e tradições. Dentro da abordagem na academia, nos mostram que $70 \%$ dos entrevistados entende que de $5 \%$ a menos das disciplinas cursadas ou em curso estão considerando as peculiaridades dos povos da Amazônia. Entretanto, percebe-se que $40 \%$ dos estudantes que estão no $3^{\circ}$ semestre entendem que de $16 \%$ a $25 \%$ das disciplinas ofertadas no curso consideram tal questão. Todavia, esses dados do $3^{\circ}$ semestre não são compatíveis com a realidade dos demais semestres da agronomia. Isso pode dever-se ao fato da falta de compreensão acerca da temática em função da própria inexperiência dos estudantes.

Quando se trata dos anseios por atividades remuneradas enquanto profissionais, nota-se uma preferência por parte dos estudantes do $7^{\circ}$ semestre e $9^{\circ}$ pela carreira do funcionalismo público. Os estudantes do $5^{\circ}$ semestre tem a perspectiva de se ocuparem após formados com outras atividades, em que $40 \%$ dos entrevistados assim disseram. Observa-se que para o trabalho com a agricultura familiar e a agricultura empresarial o interesse maior perpassa pelo $5^{\circ}$ semestre, em que $20 \%$ dos entrevistados disseram fazer opção pela agricultura familiar e $20 \%$ pela agricultura empresarial.

Foi perguntado se sentiam-se capazes de desenvolver atividades relacionadas a agricultura ecológica. A maioria dos estudantes do $5^{\circ}$ semestre e $7^{\circ}$ semestre, $70 \%$ e $60 \%$ dos entrevistados, respectivamente, afirmam não ter instrução suficiente para o 
desenvolvimento de atividades utilizando-se dessa abordagem. Quando se analisa o $9^{\circ}$ semestre esse dado inverte, com $60 \%$ dos estudantes se sentindo capazes de desenvolver algum trabalho com Agricultura Ecológica.

Os dados mensurados demonstram que as disciplinas que debatem o papel da mulher rural. $60 \%$ dos estudantes em processo de conclusão do curso, afirmam nunca ter participado ou visto alguma disciplina abordar o papel da mulher no meio rural. Esse número fica em $50 \%$ quando analisamos o $3^{\circ}$ e o $5^{\circ}$ semestres. $50 \%$ dos estudantes do $7^{\circ}$ semestre afirmam ter presenciado o debate sobre $\mathrm{o}$ papel da mulher de $1 \%$ a $5 \%$ das disciplinas cursadas. A maioria do universo de entrevistados afirma que a temática somente é abordada em $5 \%$ a $0 \%$ das disciplinas.

\section{CONCLUSÃO}

Considerando a ocorrência predominante, na Amazônia, da agricultura familiar como forma de organização no meio rural e uso da terra, avaliando também que sobressaem nesta mesorregião as práticas agrícolas tradicionais de cultivo, nota-se que o estudante de Agronomia carece de formação no que diz respeito às questões que tem envolvimento direto com a atual conjuntura de políticas públicas para o campo, como por exemplo, reforma agrária, pluriatividade e segurança alimentar. Observa-se uma separação da forma de produção com as demais relações estabelecidas neste meio, estas que tem uma interdependência e efeitos diretos umas nas outras.

A formação do agrônomo fica comprometida uma vez que este, segundo os dados observados, não mostra formação em métodos alternativos de agricultura em um ambiente de nova fronteira agrícola, como é o caso da Amazônia, mostra-se desprovida em mecanismos de produção que supram suas necessidades econômicas, considerem as diversidades de povos e garantam a sustentabilidade num âmbito ambiental.

A partir da inadequada formação deste profissional, nota-se que o estudante ingressa no mercado de trabalho fragilizado, pouco competitivo e não empreendedor dado que não visualiza elementos inovadores para sua realidade. Como alternativa a esta falha preparação, o graduando do curso de Agronomia tenta suprir as necessidades em conhecimentos através de adesão a projetos de pesquisa, ensino e extensão dentro e fora da instituição de ensino superior.

A discussão passa então a ser acerca da destinação do individuo pós-formado, dada a incapacidade de inovar dentro do campo, este acaba tendo como sua única alternativa o ingresso no serviço público, mantendo a condição de ausência de modernas alternativas viáveis de produção para a Amazônia. Além disso, o atendimento dos setores mais carentes de profissionais, como é o caso das pequenas propriedades que praticam a agricultura familiar, vêem-se em desvantagem quando comparado ao 
quantitativo de disciplinas que abordam a produção em larga escala com sistemas de produção encarecidos pela alta tecnologia e, portanto, inexeqüíveis para a grande maioria dos produtores.

\section{REFERÊNCIAS}

CAVALLET, V. J. A formação do Engenheiro Agrônomo em questão. In: FEAB. Formação profissional do Engenheiro Agrônomo. Brasília: FEAB/CONFEA, 1996a.

CAVALLET, V. J. A formação intelectual e o mercado de trabalho: o exercício da Agronomia em questão. In: FEAB. Formação profissional do Engenheiro Agrônomo. Brasília: FEAB/CONFEA, 1996b.

CAVALLET, V. J. Os desafios da extensão rural no presente. In: Extensão Rural: O ensino de extensão rural e o desenvolvimento sustentável. Santa Maria: UFSM, 1996c. p. 29-32.

CAVAllet, V. J. A formação do engenheiro agrônomo em questão: a expectativa de um profissional que atenda as demandas sociais do século XXI. São Paulo: USP, 1999. (Tese de Doutorado).

MILLÉO, M. V. R.; LENIAR, M.; DONI FILHO, L.; ZAGONEL, J.; VENÂNCIO, W. S. Reflexos da sociedade na formação do engenheiro agrônomo. Revista da Associação Brasileira de Educação Agrícola Superior. v. 17, n.1, 1999.

SARETTA, C. B. A Formação de Zootecnistas e o seu Viés Tecnicista. ALASRU / CONGRESO LATINOAMERICANO DE SOCIOLOGIA RURAL, $\quad 2006$. 